\section{Myocardial perfusion}

\section{scintigraphy}

Elizabeth Prvulovich MD FRCP FESC,

Consultant Physician in Nuclear Medicine, Institute of Nuclear Medicine, University

College London Hospitals NHS Trust, London

Clin Med 2006;6:263-6

\section{Basic principles}

Myocardial perfusion scintigraphy (MPS) is the only widely available method of direct assessment of myocardial perfusion. It involves intravenous injection of small amounts of a radioactive tracer at peak stress, followed by imaging of the heart with a gamma camera. There are three commercially available tracers: thallium-201 and two technetium-labelled tracers, sestamibi and tetrofosmin. All three are distributed throughout the myocardium in proportion to regional flow; the available data do not indicate a superiority of one agent over another for perfusion. ${ }^{1}$ The technetium-labelled tracers enable electrocardiogram (ECG)gated perfusion data to be acquired and perfusion and function assessed from a single study.

\section{Stress technique}

The choice of stress technique lies between maximal dynamic exercise and pharmacological stress using one of the vasodilator agents (adenosine or dipyridamole) or dobutamine, a beta-agonist. Vasodilator agents are used for most patients undergoing pharmacological stress; dobutamine is generally reserved for patients with asthma in whom both adenosine and dipyridamole are contraindicated:

- Maximal dynamic exercise is physiological and provides haemodynamic data with important prognostic value.

- Pharmacological stress is faster, requires less patient co-operation and is particularly useful in patients with restricted exercise tolerance or in whom exercise ECG data are already available.

Using one of these techniques all but a tiny minority of patients can be stressed, those with severe hypotension (systolic blood pressure $<90 \mathrm{mmHg}$ ) posing the greatest problem.

Caffeine has been shown to attenuate the response to vasodilator stress so patients scheduled for pharmacological stress testing must avoid caffeine-containing food and drink for at least 12 hours before the procedure. ${ }^{2,3}$ Dipyridamole (persantin) should be stopped for 12 hours as this can precipitate an exaggerated response to vasodilator stress. Other cardioactive medications can usually be continued without interruption.

\section{Imaging}

Patients are imaged supine with the arms raised above the head while the camera rotates around their chest over 10-20 minutes. The arms need to be raised to avoid causing attenuation in the lateral projections and for the camera to be as close as possible to the chest wall. Images are acquired after stress and when the heart is rested 3-4 hours later. Although this means that a study takes several hours to complete, total patient contact time for stress, injection and imaging is less than one hour. Reconstructed images are displayed using a colour scale as a semi-quantitative assessment of regional tracer uptake.

\section{Results}

- Homogeneous myocardial uptake of tracer indicates normal perfusion, hence the absence of a significant coronary stenosis (Fig 1).

- Defect in the stress images that normalises in the rest images (a reversible defect) indicates an inducible perfusion abnormality and normally corresponds to a functionally significant coronary stenosis.

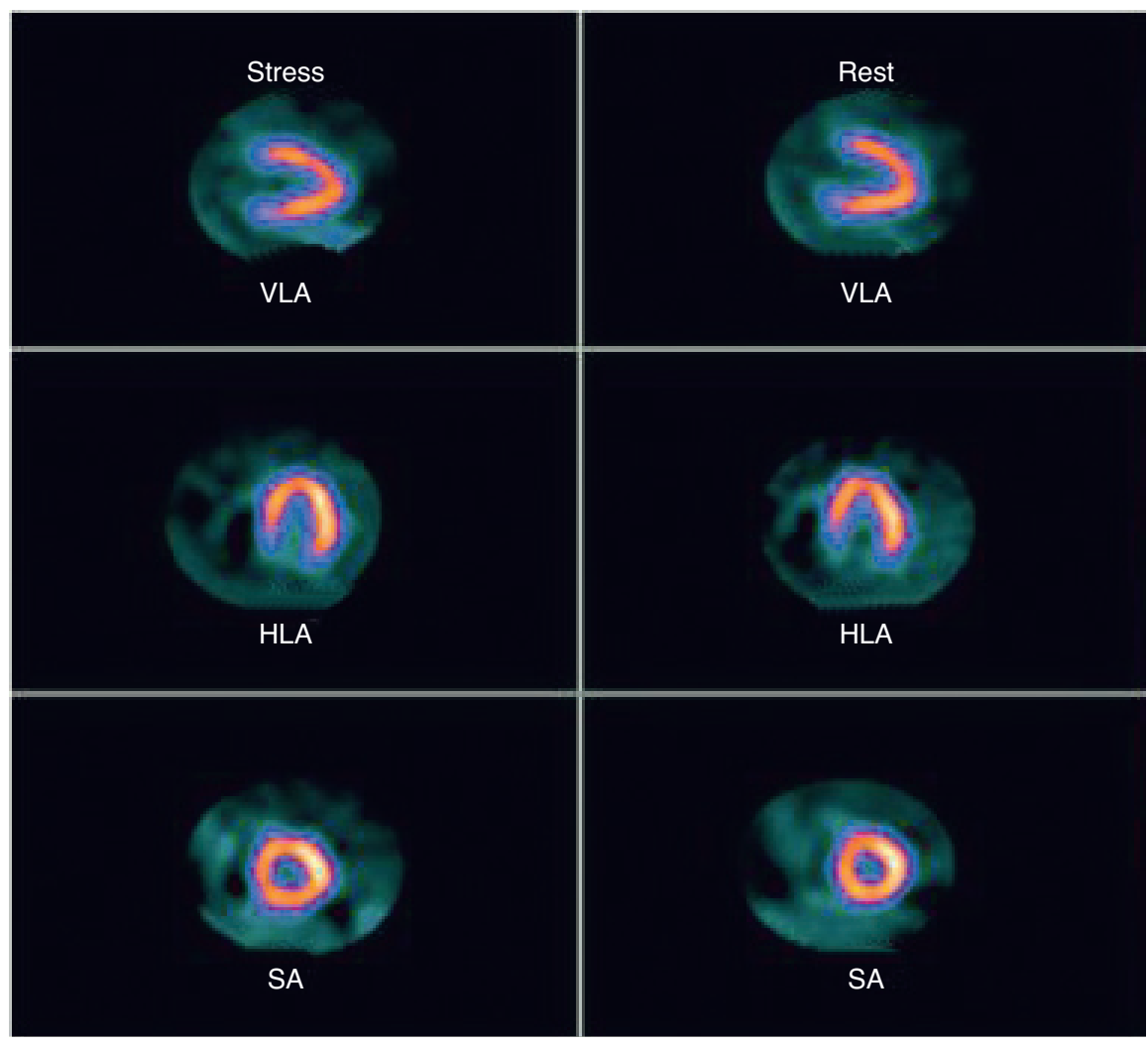

Fig 1. Normal myocardial perfusion scintigraphy. There is homogeneous tracer uptake at stress and rest. The patient is at low risk of future coronary events. HLA = horizontal long axis; $\mathrm{SA}=$ short axis; VLA = vertical long axis. 


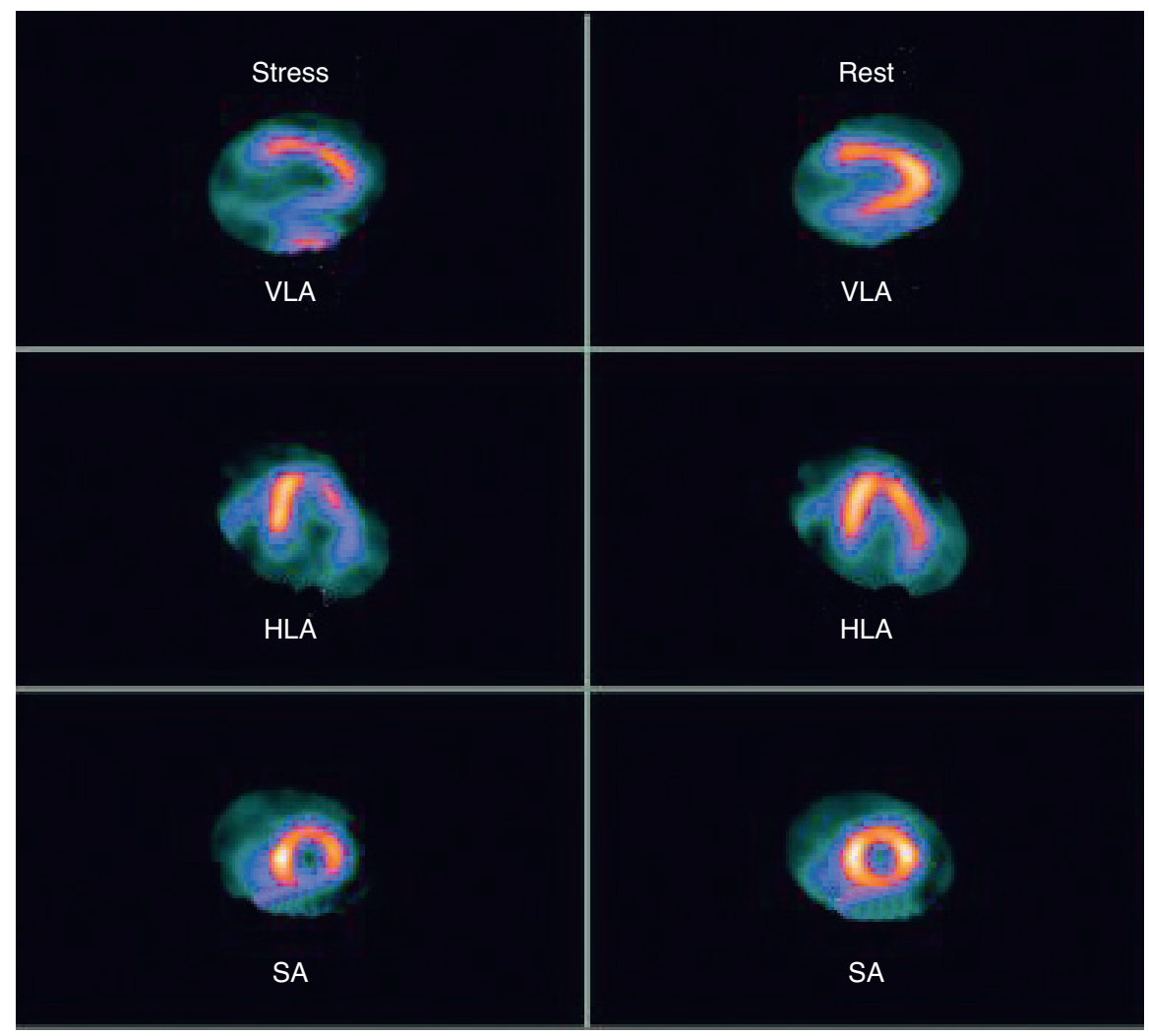

Fig 2. Abnormal myocardial perfusion scintigraphy. There is inducible ischaemia of moderate severity of the entire inferolateral region. The extent and severity of perfusion defect suggest an intermediate likelihood of future coronary events. HLA = horizontal long axis; SA = short axis; VLA = vertical long axis.

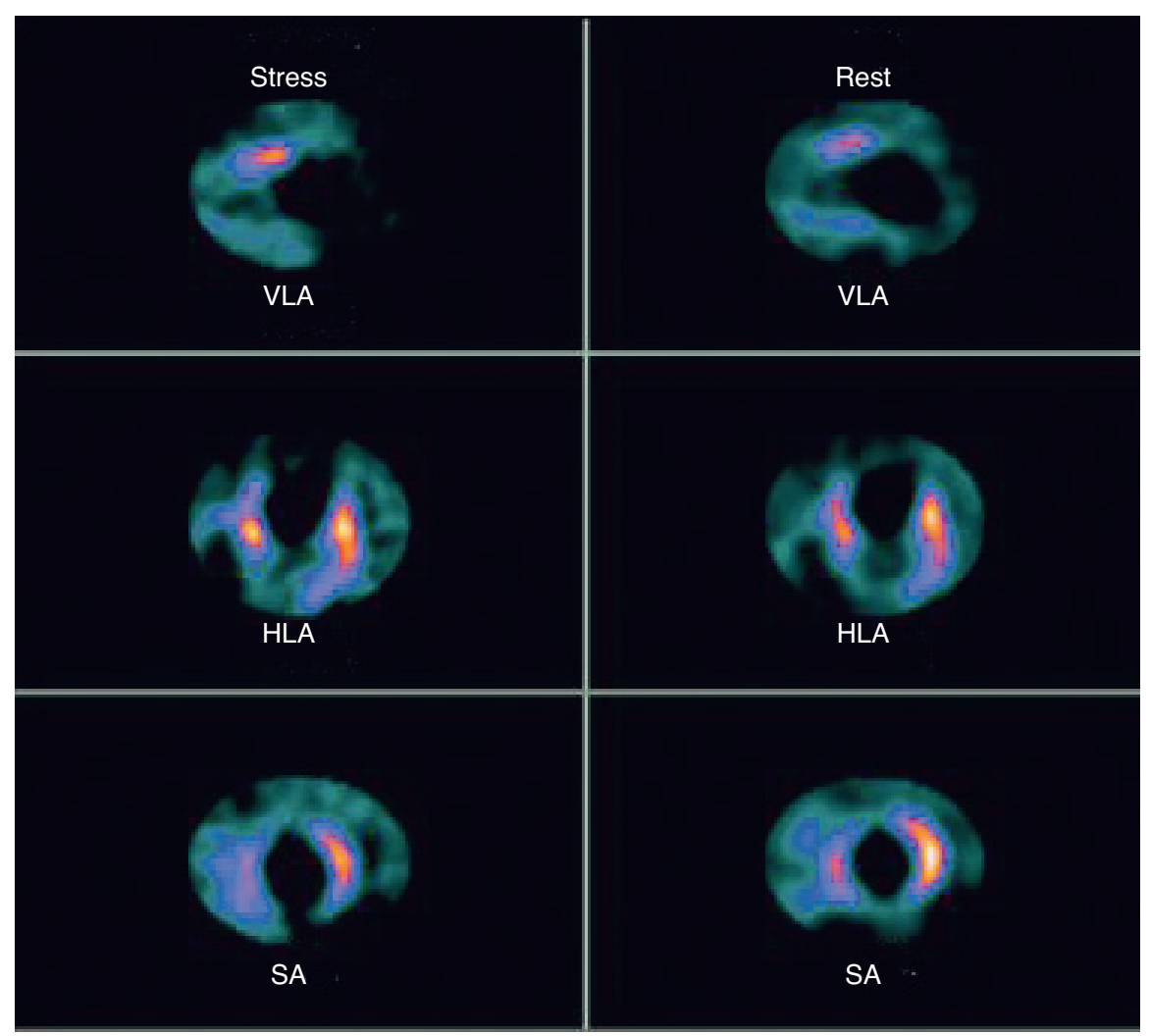

- Defect in both stress and rest images (a fixed defect) typically indicates an area of infarction.

- Anteroseptal abnormalities typically indicate disease within the left anterior descending artery.

- Lateral wall defects indicate left circumflex disease.

- Inferior wall defects are more difficult to assign as they may be supplied by either the right coronary or left circumflex artery according to dominance.

The extent and severity of abnormalities can be easily assessed and are an accurate guide to prognosis (Figs 2 and 3).

\section{Diagnosis of coronary disease}

MPS is recommended as the initial test in people presenting with stable chest pain who have restricted exercise tolerance as well as in women and those with an abnormal resting ECG in whom exercise ECG is often inconclusive. ${ }^{4,5}$ However, many centres use a staged approach to investigation using exercise ECG as the first test, reserving MPS with its higher costs and associated radiation burden for those with an intermediate risk of coronary disease after exercise testing (Table 1).

Average sensitivity and specificity for MPS based on a pooled analysis of 79 studies ( $>8,000$ patients) are $86 \%$ and $74 \%$, respectively. ${ }^{6}$ MPS provides far more, however, than a simple diagnosis. Its ability to predict future coronary events means it can be used both as a gatekeeper for coronary angiography and to drive the need for subsequent revascularisation, an approach that is both costeffective and safe in terms of subsequent clinical outcome. ${ }^{7-11}$

Fig 3. Abnormal myocardial perfusion scintigraphy. The left ventricle is dilated at stress and rest, an indicator of adverse prognosis. There is extensive infarction of the anteroapical region and inferior wall, with mild superimposed ischaemia in the basal inferior wall and mild septal inducible ischaemia. HLA = horizontal long axis; $\mathrm{SA}=$ short axis; VLA = vertical long axis. 


\section{Prognosis}

MPS has excellent negative predictive value for predicting cardiac events. Patients with a normal perfusion study have a less than $1 \%$ risk per year of important coronary events, a rate similar to that in the general population without any evidence of coronary disease. ${ }^{12}$ Thus, whether or not minor coronary disease is present, further investigation can be avoided in the absence of intractable symptoms. By contrast, patients with moderate to severely abnormal MPS have a high average event rate $(5.9 \%$ per year $)^{12}$ and would usually warrant coronary angiography. The most important variables predicting the likelihood of future events are:

- extent and severity of inducible ischaemia

- lung uptake of thallium

- stress-induced ventricular dilatation

- left ventricular ejection fraction.

In general, markers of left ventricular dysfunction tend to predict cardiac mortality while inducible ischaemia predicts acute coronary syndromes. ${ }^{13,14}$ MPS has incremental prognostic value even after clinical assessment, exercise ECG and coronary angiography. ${ }^{15}$

\section{Myocardial perfusion scintigraphy after angiography}

MPS is performed after coronary angiography to guide management in a proportion of patients. For instance, there may be a coronary stenosis of moderate severity perhaps coupled with atypical symptoms, catheter tip spasm may confuse interpretation or a vessel may be difficult to visualise in its entirety. In multivessel disease MPS may be used to guide percutaneous or surgical intervention.

\section{Myocardial perfusion scintigraphy and coronary intervention}

MPS is a useful way of risk stratifying patients before major non-cardiac surgery, the recent introduction of ECG-gated MPS allowing data regarding myocardial perfusion and function to be acquired from a single test. In patients with ischaemic left ventricular dysfunction MPS can define the need for revascularisation by determining the presence and extent of inducible ischaemia and of viable but hibernating myocardium. MPS can also be used to evaluate the success of coronary interventions and to detect inducible ischaemia in patients with recurrent angina. If the clinical situation allows, it is best to defer MPS until about two months after percutaneous intervention as there may be delayed resolution of perfusion abnormalities even after successful intervention (for reasons that remain speculative). ${ }^{16}$

\section{Myocardial perfusion scintigraphy activity}

Despite the overwhelming evidence that MPS should be routinely incorporated into diagnostic and management strategies, some centres currently use little or no MPS. Possible reasons include a lack of awareness of published guidance, a low quality local service or excessive local wait times.

Recent initiatives have addressed all three issues:

- a number of publications have detailed the evidence for MPS 17,18

Table 1. Indications for myocardial perfusion scintigraphy.

Instead of exercise ECG Resting ECG abnormal

Restricted exercise tolerance

Women

After exercise ECG
Equivocal ST changes with exercise

Exercise ECG abnormal but pretest probability of CAD low

Exercise ECG normal but pretest probability of CAD high

$\mathrm{CAD}=$ coronary artery disease $\mathrm{ECG}=$ electrocardiogram

- procedure guidelines have been prepared to guide centres in the basics of service provision ${ }^{19,20}$

- teaching aids have been designed to improve MPS reporting standards

- published advice is available on the clinical and business aspects of setting up a service for centres wishing to start or expand a nuclear cardiology service. ${ }^{21}$

\section{Quality of service provision}

Referrers can influence the quality of local MPS service provision in many ways. One imaging protocol does not suit all patients and the nuclear cardiology provider will be able to work most efficiently if it is possible to plan ahead. It is unrealistic to expect a good quality MPS service if request cards lack vital information. The following are important:

- The patient's height and weight: a heavy patient may require greater

\section{Key Points}

Myocardial perfusion scintigraphy
(MPS) is a robust method of
assessing myocardial perfusion.
Electrocardiogram (ECG)-gated MPS
allows myocardial perfusion and
function to be assessed from a
single study
MPS is a powerful predictor of
outcome in patients with coronary
artery disease and can act as the
gatekeeper to coronary
angiography
No................................................................
of future coronary events. Where
MPS is abnormal, the extent and
severity of inducible ischaemia
allow future coronary risk to be
predicted
The..........................................................
The recent National Institute for
Health and Clinical Excellence
appraisal of MPS was favourable.
MPS was recommended as the
initial diagnostic test in patients
with stable chest pain with
restricted exercise tolerance,
women and those with an abnormal
resting ECG

KEY WORDS: coronary artery disease, myocardial perfusion scintigraphy 
injected activities of tracer, whilst a very heavy patient may need to be scheduled for specific cameras equipped with couches designed to carry high weights (180 kg is about the maximum).

- An indication whether patients can exercise to high workload or have asthma to enable advance thought to be given to suitable stress techniques.

- As much information as possible about the cardiac history should be included. Most departments will try to obtain their own history, but patients are often unclear about the results of tests such as coronary angiography and details of percutaneous intervention. Succinct details from the referring physician or provision of the inpatient notes can prove invaluable.

- Asking a specific question of MPS should ensure an appropriately targeted answer is obtained.

If after all this the quality of imaging or reporting remains an issue, the local nuclear cardiology provider should be engaged in dialogue, constructive feedback on individual cases should be provided to illustrate specific points, and consideration should be given to joining a nuclear physician or radiologist working in isolation for joint reporting sessions.

\section{The future}

The future is bright for nuclear cardiology. MPS is widely regarded as a credible and useful technique for assessing myocardial perfusion and UK MPS activity is increasing apace, ${ }^{22}$ though there is still much to be done to meet the targets for service provision recommended by professional bodies and supported by the National Institute for Health and Clinical Excellence. ${ }^{4}$

Meanwhile, advances in technology mean that it is now possible to image coronary calcium, assess myocardial perfusion and function at stress and rest, and provide non-invasive angiographic data using a multislice positron emission tomography/computed tomography scanner, acquiring all the data within a single visit of less than 30 minutes. $^{23,24}$ There are exciting times ahead.

\section{References}

1 Kapur A, Latus K, Davies G et al. A comparison of three radionuclide myocardial perfusion tracers in clinical practice: the ROBUST study. Eur J Nucl Med Mol Imaging 2002;29:1608-16.

2 Smits P, Corstens FH, Aengevaeren WR, Wackers FJ, Thien T. False-negative dipyridamole-thallium-201 myocardial imaging after caffeine infusion. J Nucl Med 1991;32: 1538-41.

3 Bottcher M, Czernin J, Sun KT, Phelps ME, Schelbert HR. Effect of caffeine on myocardial blood flow at rest and during pharmacological vasodilation. J Nucl Med 1995;36: 2016-21.

4 National Institute for Health and Clinical Excellence. Myocardial perfusion scintigraphy for the diagnosis and management of angina and myocardial infarction. Technology Appraisal 73. London: NICE, 2003. www.nice.org.uk

5 de Bono D. Investigation and management of stable angina: revised guidelines 1998. Joint Working Party of the British Cardiac Society and Royal College of Physicians of London. Heart 1999;81:546-55.

6 Schuijf JD, Poldermans D, Shaw LJ et al. Diagnostic and prognostic value of non-invasive imaging in known or suspected coronary artery disease. Eur J Nucl Med Mol Imaging 2006;33:93-104.

7 Bateman TM, O’Keefe JH Jr, Dong VM, Bamhart C, Ligon RW. Coronary angiographic rates after stress single-photon emission computed tomographic scintigraphy. J Nucl Cardiol 1995;2:217-23.

8 Underwood SR, Godman B, Salyani S, Ogle JR, Ell PJ. Economics of myocardial perfusion imaging in Europe - The EMPIRE study. Eur Heart J 1999;20:157-66.

9 Shaw LJ, Hachamovitch R, Berman DS et al. The economic consequences of available diagnostic and prognostic strategies for the evaluation of stable angina patients: an observational assessment of the value of precatheterization ischemia. Economics of Noninvasive Diagnosis (END) Multicenter Study Group. J Am Coll Cardiol 1999;33: 661-9.

10 O’Keefe JH Jr, Bateman TM, Ligon RW et al. Outcome of medical versus invasive treatment strategies for non-high-risk ischemic heart disease. J Nucl Cardiol 1998;5:28-33.

11 Johansen A, Hoilund-Carlsen P, Christensen HW et al. Use of myocardial perfusion imaging to predict the effectiveness of coronary revascularisation in patients with stable angina pectoris. Eur J Nucl Med Mol Imaging 2005;32:1363-70.

12 Shaw LJ, Iskandrian AE. Prognostic value of gated myocardial perfusion SPECT. Review. J Nucl Cardiol 2004;11:171-85.

13 Hachamovitch R, Berman DS, Shaw LJ et al. Incremental prognostic value of myocardial perfusion single photon emission computed tomography for the prediction of cardiac death: differential stratification for risk of cardiac death and myocardial infarction. Circulation 1998;97:535-43.

14 Sharir T, Germano G, Kang X et al. Prediction of myocardial infarction versus cardiac death by gated myocardial perfusion SPECT: risk stratification by the amount of stress-induced ischemia and the poststress ejection fraction. J Nucl Med 2001;42:831-7.

15 Iskandrian AS, Chae SC, Heo J et al. Independent and incremental prognostic value of exercise single-photon emission computed tomographic (SPECT) thallium imaging in coronary artery disease. $J \mathrm{Am}$ Coll Cardiol 1993;22:665-70.

16 Manyari DE, Knudtson M, Kloiber R, Roth D. Sequential thallium-201 myocardial perfusion studies after successful percutaneous transluminal coronary artery angioplasty: delayed resolution of exercise-induced scintigraphic abnormalities. Circulation 1988;77:86-95.

17 Anagnostopoulos CA, Underwood R. Myocardial perfusion scintigraphy: the evidence. Heart 2004;90(Suppl 5):v1-40.

18 Underwood SR, Anagnostopoulos CA, Cerqueira $\mathrm{M}$ et al. Myocardial perfusion scintigraphy: the evidence. Review. Eur $J$ Nucl Med Mol Imaging 2004;31:261-91.

19 Anagnostopoulos CA, Harbinson M, Kelion A et al. Procedure guidelines for radionuclide myocardial perfusion imaging. Heart 2004;90(Suppl 1):i1-10.

20 Hesse B, Tagil K, Cuocolo A et al. EANM/ESC procedural guidelines for myocardial perfusion imaging in nuclear cardiology. Eur J Nucl Med Mol Imaging 2005;32:855-97.

21 Anagnostopoulos C, Davies G, Flint J et al. Setting up a myocardial perfusion scintigraphy service: clinical and business aspects. Review. Heart 2005;91(Suppl 4):iv6-14.

22 Kelion D, Anagnostopoulos C, Harbinson M, Underwood SR, Metcalfe M. Myocardial perfusion scintigraphy in the UK: insights from the British Nuclear Cardiology Society Survey 2000. Heart 2005;91(Suppl 4):iv2-5.

23 Schwaiger M, Ziegler S, Nekolla SG PET/CT: challenge for nuclear cardiology. Review. J Nucl Med 2005;46:1664-78.

24 Bateman TM. Cardiac positron emission tomography and the role of adenosine pharmacologic stress. Review. Am J Cardiol 2004;94:19D-24D. 